\section{BAD SCIENCE: OIL PULLING}

\section{Is oil pulling a miracle cure, snake oil or harmless and healthy? asks Anthony King.}

\section{What is oil pulling?}

This is the practice of swirling oil around your mouth and then spitting it out. It usually involves coconut oil, sunflower oil or sesame seed oil. Rinsing should be continued for perhaps five to 20 minutes, so that the edible oil is pulled through the teeth and mouth.

\section{Where does the practice of oil pulling come from?}

A traditional remedy originated from traditional Ayurvedic medicine in India. It has become popular after its benefits were extolled online. Promoters say the oil pulls out toxins, which are known as 'ama' in Ayurvedic medicine.

\section{What are the reputed benefits of} oil pulling?

Various websites advocate coconut oil pulling as an effective way to whiten teeth and remove bacteria. Some advocates online suggest it can treat tooth decay, kill bad breath, heal bleeding gums, prevent cavities and even prevent heart disease. There is a book, entitled Oil pulling therapy, ${ }^{1}$ that promises it exerts a powerful cleansing and healing effect on the mouth and sinuses and the rest of the body.

\section{Is there evidence for oil pulling} offering benefits to dental hygiene?

There are plenty of testimonials available online from people who praise its use, but scientific evidence is lacking. One recent review $^{2}$ found that oil pulling might be as effective as chlorhexidine mouthwash in reducing plaque. First study author, Oghenekome Gbinigie at the Centre for Evidence-based Medicine, University of Oxford, UK, said: 'At present there isn't enough information about the benefits and potential harms of oil pulling to help us decide whether or not we should take on daily oil pulling, in addition to tooth brushing.'

Another review ${ }^{3}$ looked at the oil pulling literature and identified 21 studies, but concluded that only six had proper study design. The reviewer concluded that the studies were unreliable, sometimes due to poor study design or small sample science. There is a need for bigger trials, of longer duration and of high quality.

\section{Are there potential downsides for patients using oil pulling?}

There are few reported side effects from oil pulling, but some have drawn attention to case reports of lipoid pneumonia associated with oil pulling or mineral oil aspiration. Upset stomach has also been reported. More trial data is required to provide evidence of possible side effects.

\section{Is oil pulling an alternative to brushing} or other dental hygiene practices?

Though some oil pulling advocates say it can be used instead of tooth brushing, many say it should be used together with regular dental hygiene practices. There is no evidence to support it as a substitute to tooth brushing. The
American Dental Association has stated that there is insufficient research to support the practice of oil pulling.

\section{Can oil pulling be labelled as pseudoscience?}

The author of the book Oil pulling therapy, Bruce Fife, says it can help with allergies, asthma, chronic fatigue, diabetes and migraine headaches. Others ${ }^{4}$ say it can improve acne, strengthen gums and jaws and heal bleeding gums. The expansiveness of the claims seems suspicious.

There is no evidence that oil pulling can prevent cavities, detoxify the body, strengthen teeth, treat cancer or reduce headaches, despite such claims made online. Many of these reputed benefits reek of pseudoscience quackery of the worse kind, promising exceptional health benefits without scientific evidence to support them.

Whether the practice of oil pulling can make a positive contribution to good dental hygiene is uncertain. A recent review ${ }^{2}$ suggested that it may have beneficial effects in dental hygiene, but requires more rigorous and better reported clinical trials.

1. Fife B N D. Oil pulling therapy: detoxifying and healing the body through oral cleansing. US: Piccadilly Books, 2008.

2. Gbinigie O, Onakpoya I, Spencer E, McCall MacBain M, Heneghan C. Effect of oil pulling in promoting oro dental hygiene: A systematic review of randomized clinical trials. Complement Ther Med 2016; 26: 47-54.

3. Mythri H. Oil pulling: A traditional method on the edge of evidence. Dent Hypotheses 2017; 8: 57-60.

4. Dr. Axe Food is Medicine. Coconut Oil Pulling Benefits \& How-to Guide. Available at: https:// draxe.com/oil-pulling-coconut-oil/ (accessed March 2018)

\title{
EXHIBITION TO FOCUS ON OUR EVOLVING RELATIONSHIP WITH OUR TEETH
}

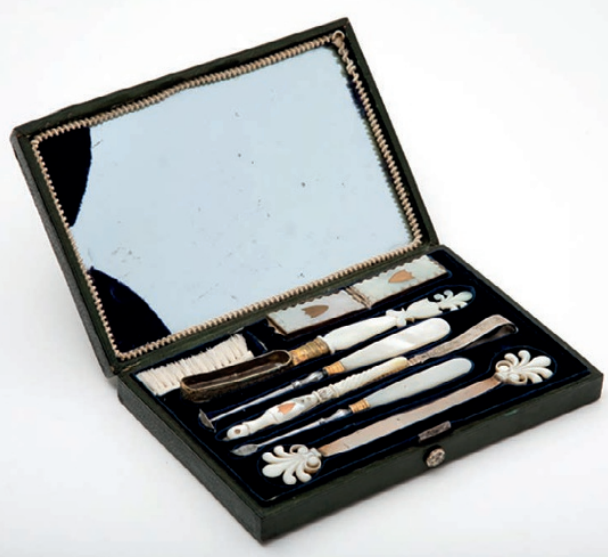

The forthcoming exhibition 'Teeth' at the Wellcome Collection in London will trace 'the evolution of our relationship with our teeth and with the profession that has shaped the way we live with them - or without them.

The exhibition, which runs from 17 May to 16 September 2018, will follow modern history's tireless pursuit of the pain-free mouth and the perfect smile. It will draw on the wealth of images, objects and artworks held in the collections held by Henry Wellcome, supplemented by loans from key collections in Northern Europe.

The BDA Museum is delighted to be lending objects to the Teeth exhibition. Highlights from the BDA collection include the dental instrument set of Sir Edwin Saunders (dentist to Queen Victoria); a denture of King William IV made by dentist Isaac Wilson of Bath; dental health education posters which are currently providing the inspiration for BDJ covers; 1960s dental surgery equipment; and an early portable regulating ether inhaler.

For more information on the exhibition visit https://wellcomecollection.org/press/ teeth-forthcoming-exhibition-wellcomecollection. 